\title{
PERFORMANCE DE FERTILIZANTES FOLIARES E CORRELAÇÕES LINEARES EM COMPONENTES DO RENDIMENTO DA SOJA
}

\author{
Vinícius Jardel Szareski ${ }^{1}$ \\ Mauricio Ferrari ${ }^{2}$ \\ Maicon Nardino ${ }^{3}$ \\ Ivan Ricardo Carvalho ${ }^{4}$ \\ Alan Junior de Pelegrin ${ }^{5}$ \\ Gustavo Henrique Demari ${ }^{6}$ \\ Diego Nicolau Follmann ${ }^{7}$ \\ Daniela Meira $^{8}$ \\ Carine Meier ${ }^{9}$ \\ Velci Queiróz de Souza ${ }^{10}$
}

Resumo: O objetivo foi avaliar a resposta de diferentes fertilizantes foliares aplicados na cultura da soja e as associações lineares entre os componentes do rendimento de grãos, nas condições edafoclimáticas da Região do Alto Uruguai, RS. O experimento foi conduzido em delineamento de blocos casualizados, com três repetições. Os tratamentos testados foram: T1: sem aplicação de bioestimulantes; T2: aplicação de NITAMIN ${ }^{\circledR}$; T3: aplicação de BIOZIME ${ }^{\circledR}$; T4: aplicação de Bioamino Extra ${ }^{\circledR}$; T5: Aplicação de NIPHOKAN®, onde avaliou-se os componentes do rendimento de grãos da soja. A aplicação de micronutrientes e bioestimulantes via foliar não acarreta em aumento no rendimento de grãos da soja, para as condições edafoclimáticas da Região do Alto Uruguai. O rendimento de grãos apresenta correlação positiva com o número de ramificações, número de legumes nas ramificações, número total de legumes, número de grãos por planta e massa de mil grãos.

Palavras-chave: Associações; Bioestimulantes; Glycine max L.; Micronutrientes.

\footnotetext{
1 Universidade Federal de Pelotas/Departamento de Ciências e Tecnologia de Sementes, Brasil. E-mail: viniciusszareski@gmail.com.

2 Universidade Federal de Pelotas/Departamento de Fitotecnia, Brasil. E-mail: ferraritatu@gmail.com.

3 Universidade Federal de Pelotas/Departamento de Física e Matemática, Brasil. E-mail: nardinomn@gmail.com.

4 Universidade Federal de Pelotas/Departamento de Fitotecnia, Brasil. E-mail: carvalho.irc@gmail.com.

5 Universidade Federal de Pelotas/Departamento de Fitotecnia, Brasil. E-mail: pelegrinagro@gmail.com.

6 Universidade Federal de Pelotas/Departamento de Ciências e Tecnologia de Sementes, Brasil. E-mail: deolhonaagricultura@gmail.com.

7 Universidade Federal de Santa Maria/Departamento de Fitotecnia, Brasil. E-mail: diegonicolaufollmann@gmail.com.

8 Universidade Federal de Santa Maria, campus de Frederico Westphalen/Departamento de Ciências Agronômicas e Ambientais, Brasil. E-mail: dmdanielameira94@gmail.com.

9 Universidade Federal de Santa Maria, campus de Frederico Westphalen/Departamento de Ciências Agronômicas e Ambientais, Brasil. E-mail: meiercarine5@gmail.com.

10 Universidade Federal do Pampa, campus de Dom Pedrito, Brasil. E-mail: velciq@gmail.com.
} 